\title{
Zoledronic acid increases the antitumor effect of gefitinib treatment for non-small cell lung cancer with EGFR mutations
}

\author{
CHENGJUN FENG ${ }^{1,2}$, XIAOKE LIU ${ }^{1}$, XIAOYU LI ${ }^{1}$, FUCHUN GUO $^{1}$, CHUYING HUANG $^{1,3}$, \\ QING QIN $^{1}$ and YONGSHENG WANG ${ }^{1}$ \\ ${ }^{1}$ Department of Thoracic Oncology, Cancer Center, State Key Laboratory of Biotherapy, \\ West China Hospital, Sichuan University, Chengdu, Sichuan 610041; ${ }^{2}$ Department of Oncology, \\ Taizhou People's Hospital, Taizhou, Jiangsu 225300; ${ }^{3}$ Department of Medical Oncology, \\ Enshi Tujia and Miao Autonomous Prefecture Central Hospital, Enshi, Hubei 445000, P.R. China
}

Received September 23, 2015; Accepted October 31, 2015

DOI: $10.3892 /$ or.2016.4741

\begin{abstract}
Non-small cell lung cancer (NSCLC) patients with epithelial growth factor receptor (EGFR) mutations and bone metastases are often concurrently administered tyrosine kinase inhibitors (TKIs) and bisphosphonates. Yet, the effects and mechanisms of these agents are unclear. In the present study, we aimed to ascertain whether zoledronic acid (ZA) increases the antitumor effects of gefitinib treatment on NSCLC with EGFR mutations and the related mechanisms of action. The effects of ZA and gefitinib on NSCLC tumor cells with EGFR mutations (HCC827, HCC827 GR and H1975) in regards to proliferation, apoptosis, cell cycle and signaling pathways were detected. ZA increased the antitumor effects of gefitinib on NSCLC with EGFR activating mutations and TKI resistance in vitro. Gefitinib caused cell cycle arrest in the G0/G1 phase, ZA induced S phase accumulation and the effect of the combined treatment was neutralization. Combined treatment obviously inhibited STAT3 and/or p-STAT3 protein expression compared with treatment with each single drug in vitro and in vivo, and it also significantly inhibited TKI
\end{abstract}

Correspondence to: Professor Yongsheng Wang, Department of Thoracic Oncology, Cancer Center, State Key Laboratory of Biotherapy, West China Hospital, Sichuan University, 37 Guoxue Xiang Road, Chengdu, Sichuan 610041, P.R. China

E-mail: wangys@scu.edu.cn

Abbreviations: EGFR, epithelial growth factor receptor; TKI, tyrosine kinase inhibitor; NSCLC, non-small cell lung cancer; ZA, zoledronic acid; BPs, bisphosphonates; FPP, farnesyl pyrophosphate; PFS, progression-free survival; OS, overall survival; STAT3, signal transducer and activator of transcription 3; ERK, extracellular regulated protein kinase; Akt, protein kinase B; MTT, 3-(4,5-dimethyl-2-thiazolyl)-2,5-diphenyl-2-H-tetrazolium bromide; DMSO, dimethyl sulfoxide; IHC, immunohistochemistry; IOD, intensity optical density

Key words: zoledronic acid, gefitinib, non-small cell lung cancer, epithelial growth factor receptor mutation, signal transducer and activator of transcription 3 resistance NSCLC tumor growth in vivo. In conclusion, ZA increased the antitumor effects of gefitinib on NSCLC with EGFR activating mutations and TKI resistance by regulating the cell cycle, inducing caspase-3 expression and inhibiting STAT3 expression.

\section{Introduction}

Lung cancer is the most common malignant tumor in the world and seriously affects human health due to the poor prognosis of these patients (1). Non-small cell lung cancer (NSCLC) is the main pathological type of lung cancer. Approximately $10-15 \%$ of NSCLC patients harbor epithelial growth factor receptor (EGFR) mutations while, it is as high as $30-40 \%$ in East Asian patients (2-4). The most common EGFR mutations are exon 19 deletions (19 del) and exon 21 L858R point mutations (L858R), together representing $90 \%$ of all mutations $(2,4)$. EGFR tyrosine kinase inhibitors (EGFR-TKIs) have been approved for NSCLC patients harboring EGFR activating mutations as first-line therapy, and the response rate is as high as $\sim 75 \%(3,5)$. Yet, almost all of the patients present with TKI resistance. Drug resistance mechanisms include exon 20 point mutation (T790M), c-met amplification, PI3K persistent activation and hepatocyte growth factor (HGF) overexpression (6). T790M mutations and c-met amplifications account for approximately $75 \%$ of all TKI resistant cases (6-8). To date, there are a lack of treatment methods to overcome TKI resistance in the clinic.

Zoledronic acid (ZA) is a third-generation nitrogencontaining bisphosphonate and is widely used in the treatment of malignant tumors with bone metastases. The mechanism involves inhibition of farnesyl pyrophosphate (FPP) synthase function in the mevalonate pathway, and it inhibits the activity of osteoclasts and induces osteoclast apoptosis $(9,10)$. ZA has shown antitumor effects in many tumor cells, including NSCLC $(11,12)$. Meanwhile, it can increase the antitumor effects in combination with chemotherapy and radiotherapy $(13,14)$. The antitumor mechanisms include inhibition of the mevalonate pathway, affecting tumor signaling pathways, regulation of immune response and anti-angiogenesis $(12,13)$. 
NSCLC patients with EGFR mutations and bone metastases are often concurrently administered ZA and EGFR-TKI. Our retrospective clinical study found that bisphosphonates (BPs) can improve the progression-free survival and overall survival of advanced NSCLC patients with EGFR mutations and bone metastases undergoing EGFR-TKI treatment (15). A preclinical study also found that ZA can increase the antitumor effect of gefitinib treatment for NSCLC with EGFR activating mutations (16). Yet the mechanism needs further research. In addition, the effects and mechanisms of ZA and EGFR-TKI treatment in TKI-resistant NSCLC are unclear. Therefore, we explored whether ZA could increase the antitumor effects of gefitinib treatment for NSCLC with EGFR activating mutations and TKI resistance and the related mechanisms.

\section{Materials and methods}

Reagents. Gefitinib was purchased from Biochempartner (Shanghai, China) and ZA was kindly provided by Novartis Pharma Stein AG (Basel, Switzerland). The Annexin V-FITC Apoptosis Detection kit was purchased from BD Pharmingen (San Diego, CA, USA). Primary antibodies, EGFR, p-EGFR (Tyr1173), p44/42 MAPK (ERK1/2), p-p44/42 MAPK (Thr202/Tyr204), Akt, p-Akt (Ser473), STAT3, p-STAT3 (Tyr705), p-STAT3 (Ser727), caspase-3, $\beta$-actin and $\beta$-tubulin were purchased from Cell Signaling Technology, Inc. (Beverly, MA, USA). The horseradish peroxidase (HRP)-conjugated secondary antibody and immunohistochemical detection kit were purchased from ZSGB-BIO (Beijing, China).

Cell lines. The human lung adenocarcinoma cell lines HCC827, HCC827 GR and H1975 were used in the present study. HCC827 harbors an EGFR exon 19 in-frame deletion (E746-A750). HCC827 GR is a gefitinib-acquired resistant cell line that was established by chronic exposure of HCC827 cells to medium with increasing concentrations of gefitinib. H1975 harbors an EGFR exon 21 point mutation of L858R and an EGFR exon 20 mutation of T790M.

Cell cytotoxicity assay. The effects of gefitinib and ZA on the proliferation of the NSCLC cells were detected by MTT assay. Briefly, $5 \times 10^{3}$ cells per well were seeded in 96-well plates and treated with gefitinib and/or ZA. After 48 h, $20 \mu \mathrm{l}$ of MTT reagent $(5 \mathrm{mg} / \mathrm{ml})$ was added to each well and incubated at $37^{\circ} \mathrm{C}$ for $3 \mathrm{~h}$. The medium was removed and $150 \mu \mathrm{l}$ DMSO was added to each well. Cell proliferation was evaluated by a microplate reader at a wavelength of 570 and $630 \mathrm{~nm}$. Six replicates were prepared for each sample, and experiments were conducted in triplicate.

Detection of cell apoptosis. Cells were seeded at $2 \times 10^{5}$ per well in 6-well plates and treated with gefitinib and/or ZA. After $48 \mathrm{~h}$, the cells were harvested. The method of staining was in accordance with the manufacturer's instructions. Cell apoptosis was analyzed by a Becton Dickinson FACSCalibur flow cytometer, and data were analyzed by FlowJO software. All of the experiments were repeated thrice independently.

Analysis of cell cycle distribution. Cells were seeded at $2 \times 10^{5}$ per well in 6 -well plates and treated with gefitinib and/or ZA. After 24 or $48 \mathrm{~h}$, the cells were collected and washed with ice-cold phosphate-buffered saline (PBS), fixed in $75 \%$ ethanol at $4^{\circ} \mathrm{C}$ for $12 \mathrm{~h}$ and then washed twice with PBS. Cells were stained at $4^{\circ} \mathrm{C}$ for $30 \mathrm{~min}$ with PI $(50 \mu \mathrm{g} / \mathrm{ml}$ in PBS), and 2.0x $10^{4}$ cells were analyzed using a FACSCalibur flow cytometer. DNA histograms were analyzed using ModFit LT software.

Western blot assay. Cells were pretreated with gefitinib and/or ZA for 4 or $24 \mathrm{~h}$, and protein expression was analyzed by western blot analysis as previously described (17).

In vivo study. Six- to eight-week-old female athymic (BALB/c, nu/nu) mice were used in this experiment. The animal experiment was carried out according to protocols approved by Sichuan University's Institutional Animal Care and Use Committee. HCC827 GR and H1975 xenografts were established in athymic mice by subcutaneous injection of $7 \times 10^{6}$ cancer cells into the right flank of the nude mice. When the volume of the tumor reached $\sim 50 \mathrm{~mm}^{3}$, the mice were divided into control, gefitinib, ZA and gefitinib combined with ZA groups (9-10 mice per group) and treatment continued for 6 or 7 weeks. Tumor weight, tumor size and body weight were measured every 3 days during the treatment period. Tumor volume was calculated by the formula: $\mathrm{V}=0.52 \mathrm{x}$ (length $\mathrm{x}$ width ${ }^{2}$ ). Gefitinib suspended in $50 \%$ polyethylene glycol (PEG) 400 in water was administered daily at $50 \mathrm{mg} / \mathrm{kg} /$ day by oral gavage and ZA stock solution diluted in PBS was administered twice per week at $80 \mu \mathrm{g} / \mathrm{kg}$ by i.p. injection. Mice in the combined treatment group received gefitinib and ZA treatment at the same time. Mice in the control group were given the same volumes of 50\% PEG 400 by oral gavage. At the end of the experiment, all mice were sacrificed.

Immunohistochemistry. The protein expression of tumor tissues was evaluated by immunohistochemistry (IHC) as previously described (18). As negative control, PBS was used to replace the primary antibody. The protein expression in the cytoplasm was analyzed by Image Pro Plus 6 software and was expressed as mean intensity optical density (IOD). The protein expression in nuclei was analyzed by counting the proportion of positively stained nuclei.

Statistical analysis. The results of continuous data were expressed as the mean \pm standard deviation (SD). Differences between multiple groups were detected through an one-way ANOVA test. $\mathrm{P}<0.05$ was considered to indicate a statistically significant difference.

\section{Results}

Zoledronic acid and gefitinib inhibit the proliferation of NSCLC cell lines with EGFR mutations. First, the antitumor effects of gefitinib and ZA on NSCLC with EGFR mutations were detected by MTT assay. The $\mathrm{IC}_{50}$ values of gefitinib treatment in the HCC827, HCC827 GR and H1975 cells at $48 \mathrm{~h}$ were $18.22 \pm 0.45 \mathrm{nM}, 8.40 \pm 1.22 \mu \mathrm{M}$ and $17.94 \pm 1.77 \mu \mathrm{M}$, respectively (Fig. 1A, D and G). The $\mathrm{IC}_{50}$ value for $\mathrm{ZA}$ treatment in the $\mathrm{H} 1975$ cells at $48 \mathrm{~h}$ was $286.89 \pm 74.91 \mu \mathrm{M}$. When the concentrations of ZA reached $80 \mathrm{nM}$ and $80 \mu \mathrm{M}$, it failed 
A
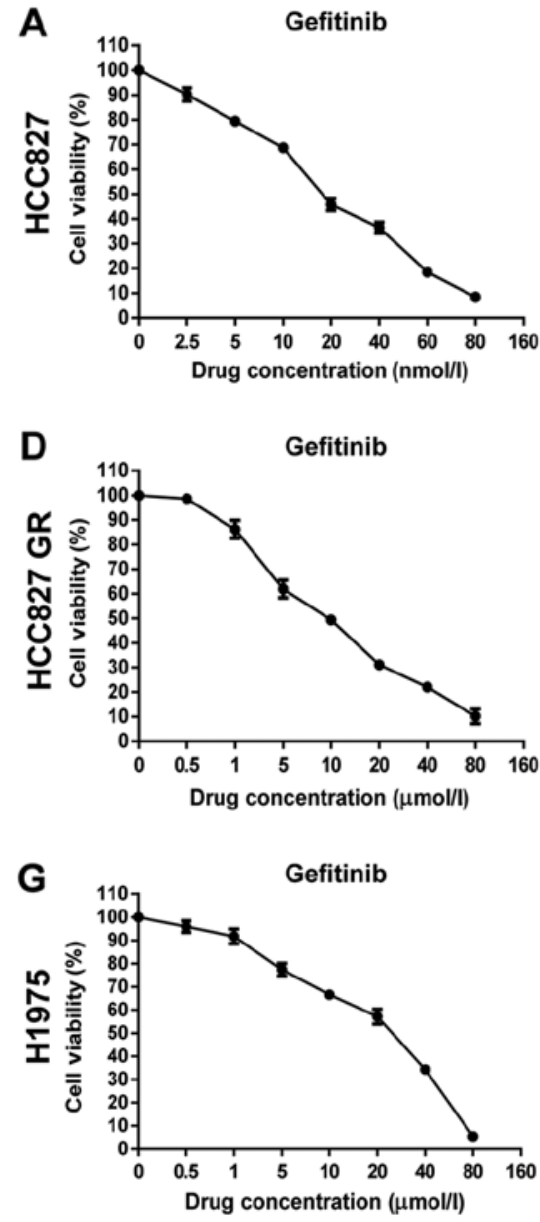

B

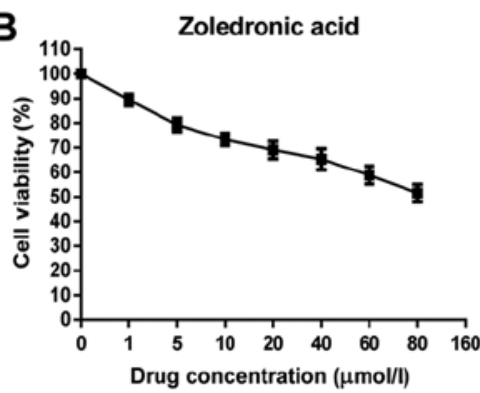

E
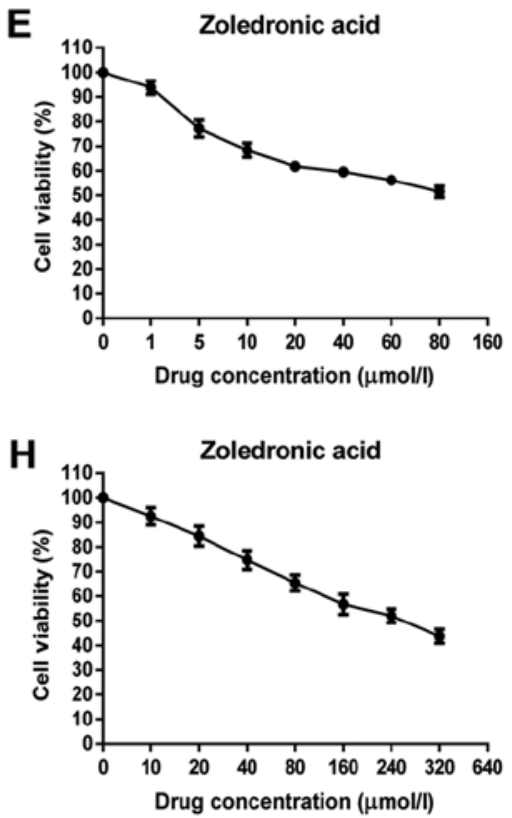

C

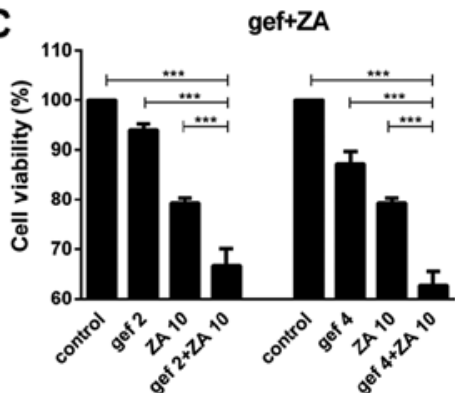

F

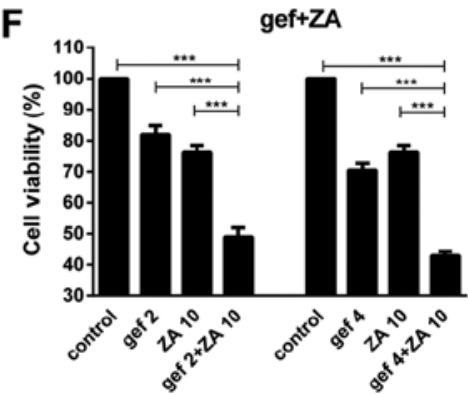

I

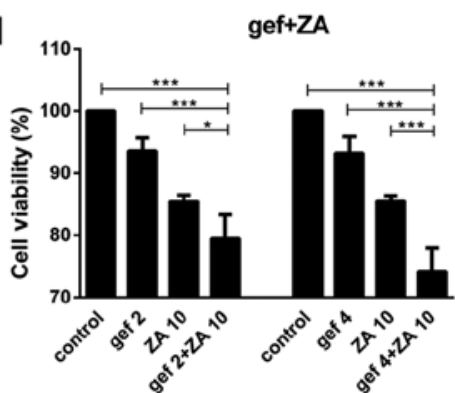

Figure 1. Gefitinib and zoledronic acid (ZA) inhibit proliferation of NSCLC tumor cells with EGFR mutations. HCC827 (A-C), HCC827 GR (D-F) and H1975 (G-I) cells were treated with gefitinib (gef) and/or ZA for $48 \mathrm{~h}$, respectively. Then cell proliferation was detected by MTT assay. In the combined treatment, gefitinib was administered at concentrations of 2 and $4 \mathrm{nM}$ in the HCC827 cells, and 2 and $4 \mu \mathrm{M}$ in the HCC827 GR and H1975 cells. ZA was administered at a concentration of $10 \mu \mathrm{M}$ in all three tumor cell lines. Each value point or bar represents the mean and standard deviation of three separate experiments. ${ }^{*} \mathrm{P}<0.05,{ }^{* * * *} \mathrm{P}<0.01$.

to reach the $\mathrm{IC}_{50}$ in $\mathrm{HCC} 827$ and HCC827 GR cells, respectively (Fig. 1B, E and H). Therefore, gefitinib or ZA alone inhibited the proliferation of the HCC 827, HCC827 GR and H1975 cells, and the effects were more obvious with increasing drug concentrations.

Then, we detected whether ZA could increase the antitumor effect of gefitinib in these cells. The results showed that the cytotoxic effect of gefitinib in all three cell lines was enhanced by co-incubation with a low concentration of ZA $(\mathrm{P}<0.05)$. Higher cytotoxic effect on the tumor cells was noted with increasing drug concentrations (Fig. 1C, F and I).

$Z A$ increases the apoptosis induced by gefitinib treatment on NSCLC cells with EGFR mutations. First, the effects of gefitinib or ZA on the induction of apoptosis in NSCLC cell lines with EGFR mutations were detected by flow cytometry. Fig. 2 shows that both gefitinib and ZA slightly induced apoptosis in the HCC827, HCC827 GR and H1975 cells. The percentage of apoptotic cells was significantly increased following combined treatment with gefitinib and ZA compared with gefitinib or ZA monotherapy $(\mathrm{P}<0.01)$. Thus ZA increased the apoptosis induced by gefitinib treat- ment in NSCLC cell lines with EGFR activating mutations and TKI resistance.

Then, we detected the effects of gefitinib and ZA on caspase-3 protein expression on NSCLC cell lines with EGFR mutations by western blot analysis. The results showed that the combined treatment with gefitinib and ZA could obviously increase caspase-3 protein expression in the HCC827, HCC827 GR and H1975 cells compared with gefitinib or ZA monotherapy (Fig. 3).

Effect of ZA and gefitinib on cell cycle progression in the NSCLC cells with EGFR mutations. We confirmed that ZA increased the antitumor effect of gefitinib treatment in NSCLC with EGFR mutations in vitro. We next detected the effects of ZA and/or gefitinib on the cell cycle. In the HCC 827 GR cells (Fig. 4), gefitinib treatment for 24 and $48 \mathrm{~h}$ increased the percentage of cells in the G0/G1 phase and decreased the percentage of cells in the $\mathrm{S}$ phase in a dose- and time-dependent manner. Gefitinib had no effect on the G2/M phase. ZA treatment at 24 and $48 \mathrm{~h}$ obviously induced $\mathrm{S}$ phase accumulation and decreased $\mathrm{G} 0 / \mathrm{G} 1$ phase accumulation of tumor cells, with increasing treatment time. More tumor cells were blocked in 

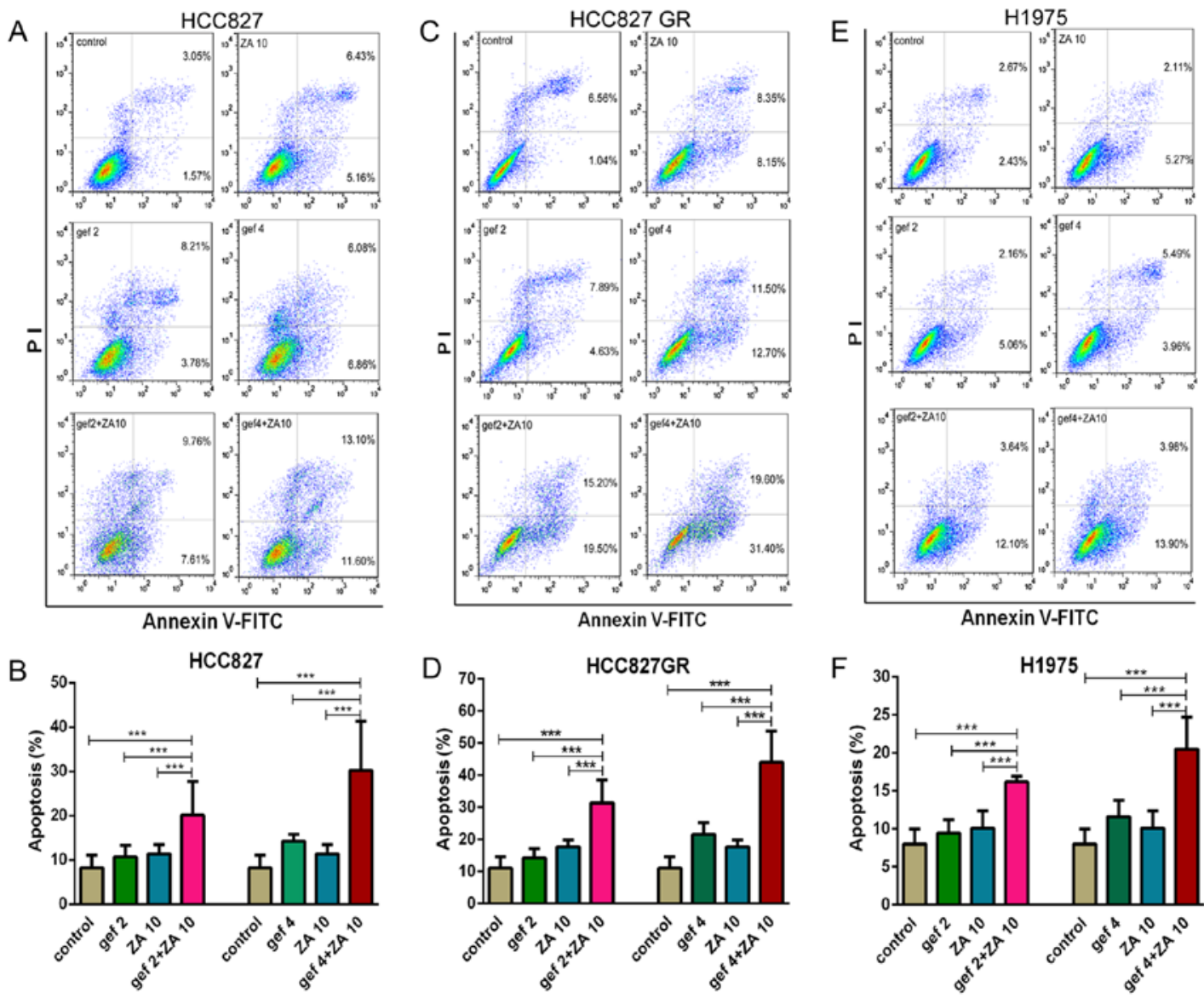

Figure 2. Gefitinib and zoledronic acid (ZA) induce the apoptosis of NSCLC tumor cells with EGFR mutations. HCC827, HCC827 GR and H1975 cells were divided into six treatment groups, treated with gefitinib (gef) and/or ZA for $48 \mathrm{~h}$. Then the tumor cells were collected and flow cytometry was used to determine the percentage of cell apoptosis. Gefitinib was administered at concentrations of 2 and $4 \mathrm{nM}$ in the HCC827 cells and at 2 and $4 \mu \mathrm{M}$ in the HCC827 GR and $\mathrm{H} 1975$ cells. ZA was administered at a concentration of $10 \mu \mathrm{M}$ in all three tumor cell lines. (A, C and E) Flow scatter diagrams from one representative experiment. (B, D and F) Histograms of three independent experiments. ${ }^{* * *} \mathrm{P}<0.01$.

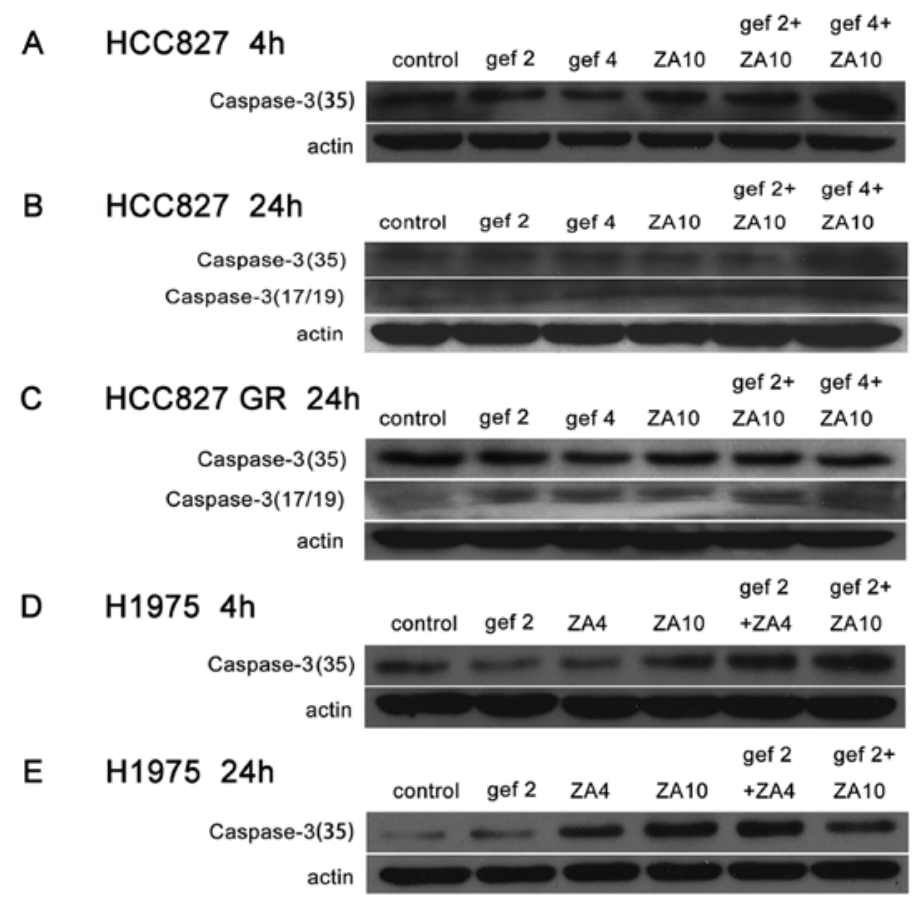

Figure 3. Effects of gefitinib and zoledronic acid (ZA) on caspase-3 protein expression of NSCLC tumor cells. (A and B) HCC827, (C) HCC827 GR and (D and E) H1975 cells were divided into six groups, treated with gefitinib (gef) and/or ZA for 4 or $24 \mathrm{~h}$. Western blot analysis was used to detect caspase-3 protein expression. Gefitinib was administered at concentrations of 2 and $4 \mathrm{nM}$ in the HCC827 cells and at 2 and $4 \mu \mathrm{M}$ in the HCC $827 \mathrm{GR}$ and $2 \mu \mathrm{M}$ in the H1975 cells. ZA was administered at a concentration of $10 \mu \mathrm{M}$ in the HCC827 and HCC827 GR cells and at 4 and $10 \mu \mathrm{M}$ in the H1975 cells. 


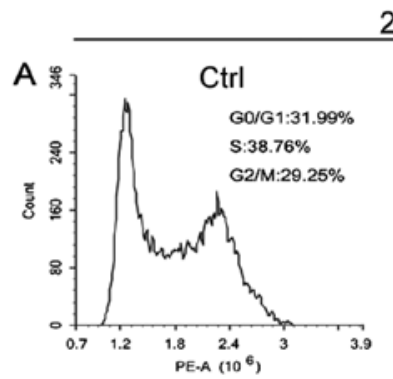

$24 \mathrm{~h}$
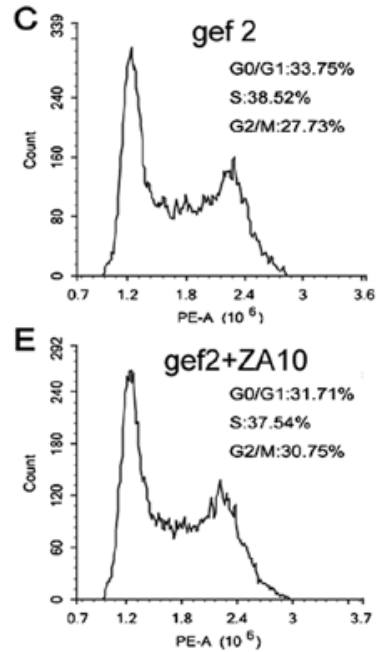

M

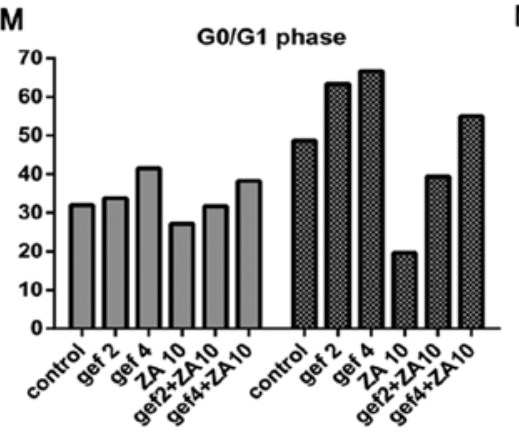

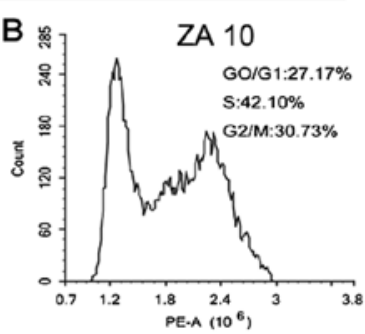
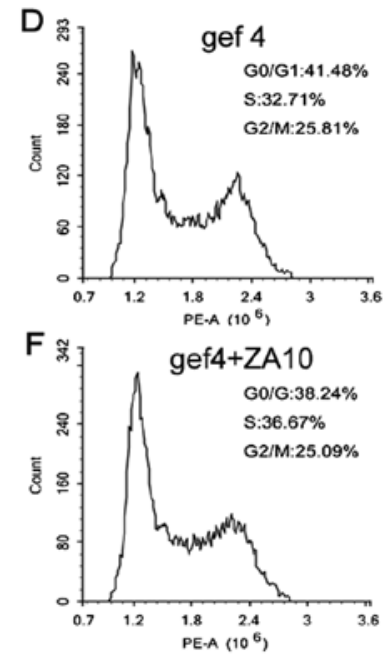

N

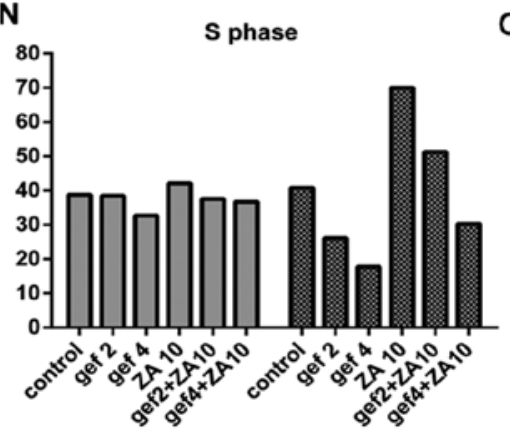

$48 \mathrm{~h}$
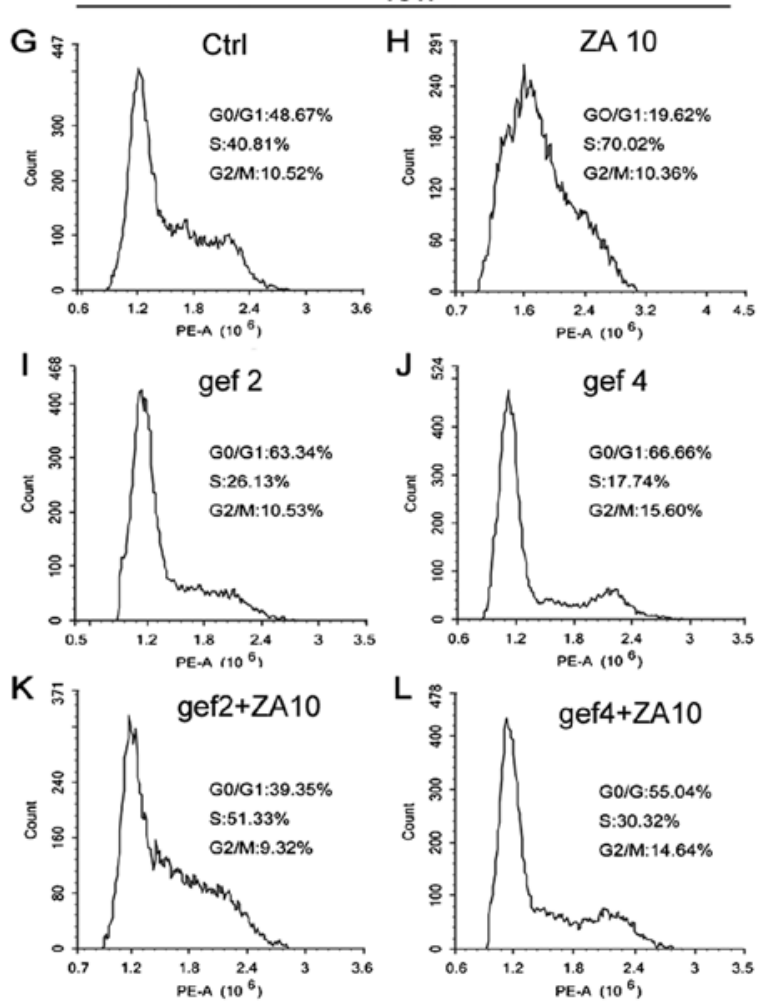

0

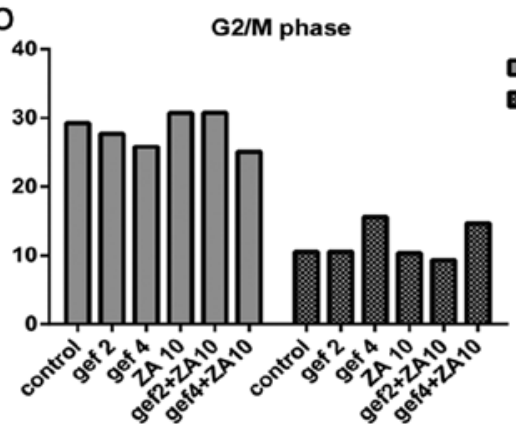

Figure 4. Effect of zoledronic acid (ZA) and gefitinib on the cell cycle of HCC827 GR cells. HCC827 GR cells were divided into six groups: control, 2 and $4 \mu \mathrm{M}$ gefitinib (gef), $10 \mu \mathrm{M} \mathrm{ZA}, 2$ and $4 \mu \mathrm{M}$ gefitinib combined with $10 \mu \mathrm{M}$ ZA. Cells were treated with the indicated agents for $24 \mathrm{~h}(\mathrm{~A}-\mathrm{F})$ or $48 \mathrm{~h}(\mathrm{G}-\mathrm{L})$, and then tumor cells were collected and flow cytometry was used to determine the cell cycle. (M-O) Histograms of tumor cells in the G0/G1, S and G2/M phase after drug treatment for 24 and $48 \mathrm{~h}$, respectively.

the $\mathrm{S}$ phase, while G2/M phase had no change. The combined treatment increased the percentage of cells in the G0/G1 phase and decreased the percentage of cells in the $\mathrm{S}$ phase compared with ZA in a dose- and time-dependent manner. The results for gefitinib and ZA on the cell cycle distribution of HCC827 (Fig. 5) and H1975 (Fig. 6) cells were similar to the results found for the HCC 827 GR cells.

Therefore, gefitinib caused HCC827, HCC 827 GR and H1975 cell cycle arrest in the G0/G1 phase. ZA arrested the cells in the $\mathrm{S}$ phase and the effects of the combined therapy on the cell cycle were neutralization.

Effects of gefitinib and/or ZA on EGFR and downstream signaling molecules in the NSCLC tumor cells. To further reveal the mechanisms of action, we detected protein expression of EGFR and downstream signaling molecules in the NSCLC cells with EGFR mutations following treatment with gefitinib and/or ZA by western blot analysis. In the
HCC827 cells (Fig. 7A), gefitinib obviously inhibited EGFR and downstream molecules Akt, STAT3 and ERK protein phosphorylation. ZA inhibited STAT3 protein expression and phosporylated Akt, STAT3 protein. The combined treatment also inhibited EGFR and downstream molecules Akt, STAT3 and ERK protein phosphorylation and slightly inhibited STAT3 protein expression. Expression of pS727-STAT3 following the combined treatment was lower than the level in the other treatment groups. In the HCC827 GR cells (Fig. 7B), ZA inhibited STAT3 protein phosphorylation. The combined treatment inhibited EGFR and downstream molecules Akt and STAT3 protein phosphorylation; among them, pS473-Akt1 and pY705-STAT3 levels were lower in the combined treatment group that levels noted in the other treatment groups. In the H1975 cells (Fig. 7C), ZA inhibited STAT3 protein expression and phosphorylation. The combined treatment inhibited EGFR and downstream molecules Akt and STAT3 protein phosphorylation and STAT3 protein expression. The expres- 
$24 \mathrm{~h}$
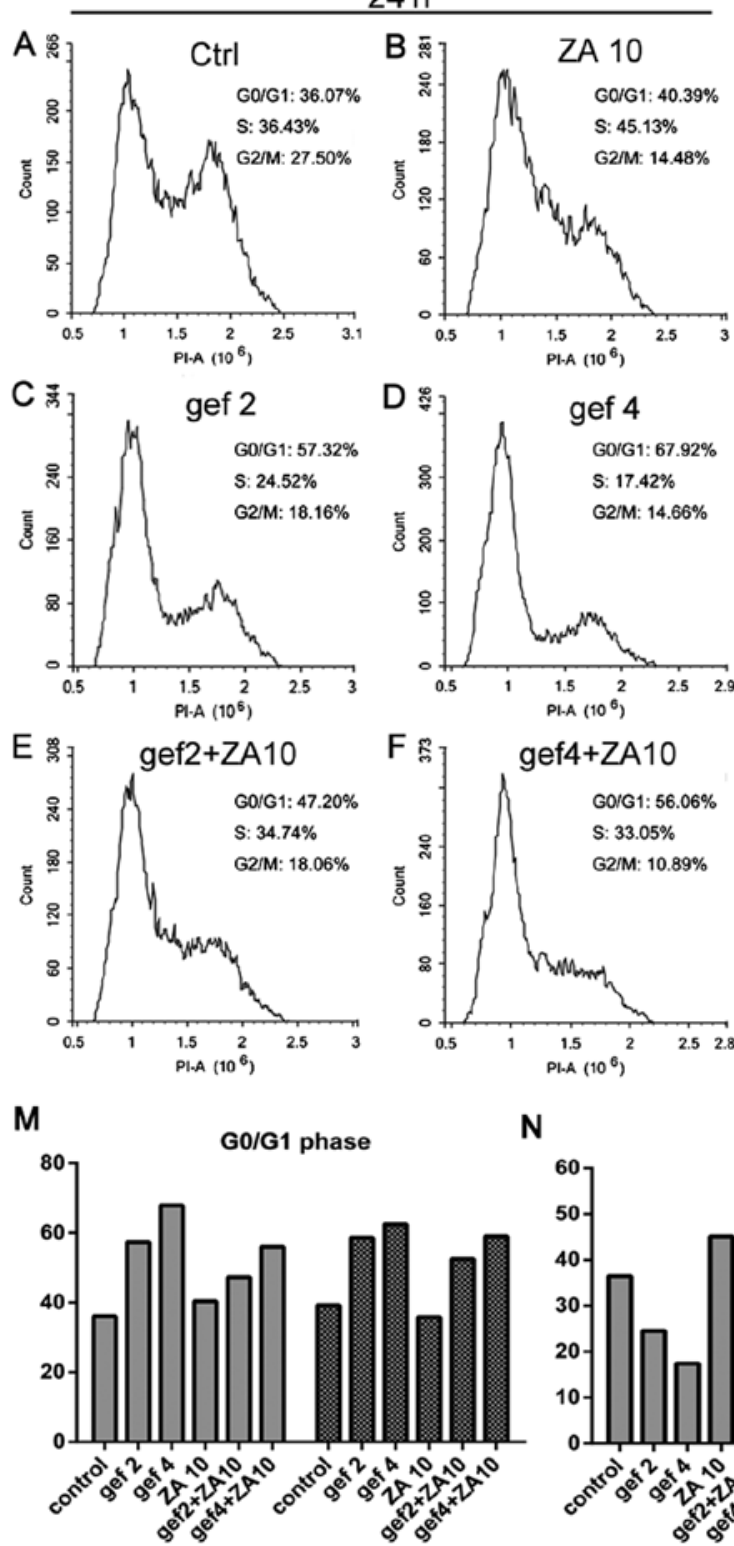
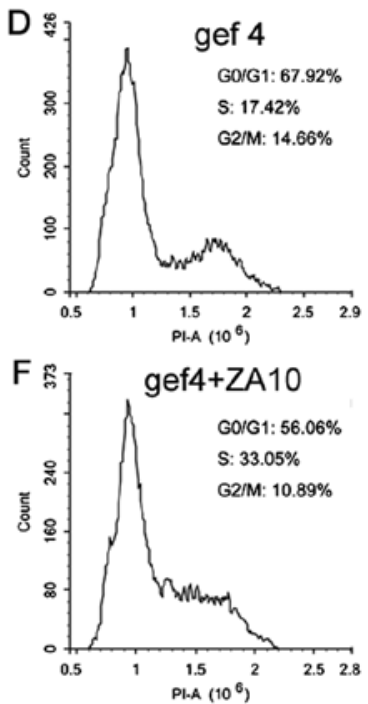

N

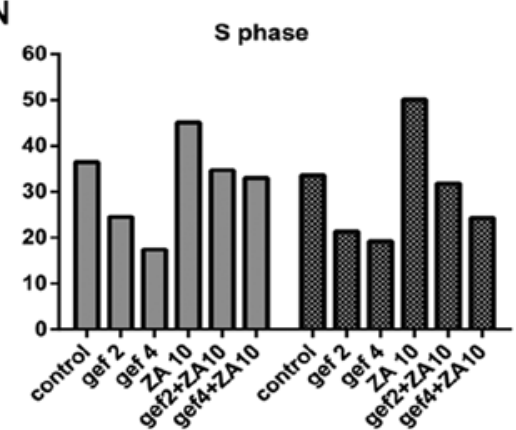

$48 \mathrm{~h}$
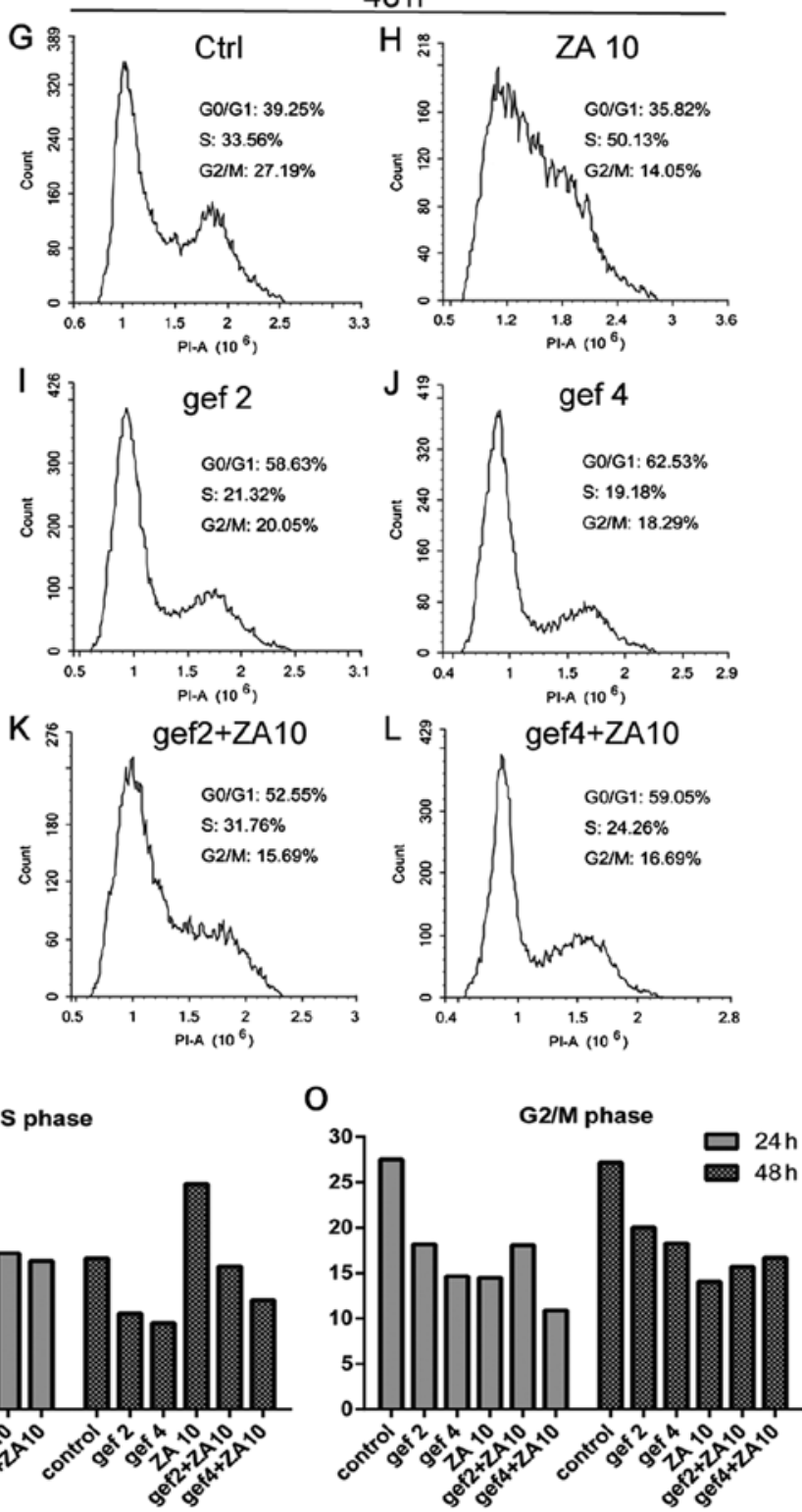

Figure 5. Effect of zoledronic acid (ZA) and gefitinib on the cell cycle of HCC827 cells. HCC827 cells were divided into six groups: control, 2 and 4 nM gefitinib (gef), $10 \mu \mathrm{M} \mathrm{ZA,} 2$ and $4 \mathrm{nM}$ gefitinib combined with $10 \mu \mathrm{M}$ ZA. Cells were treated with the indicated agents for $24 \mathrm{~h}$ (A-F) or $48 \mathrm{~h}$ (G-L), and then tumor cells were collected and flow cytometry was used to determine the cell cycle. (M-O) Histograms of tumor cells in the G0/G1, S and G2/M phase after drug treatment for 24 and $48 \mathrm{~h}$, respectively.

sion levels of these proteins were lower following combined treatment when compared with gefitinib or ZA monotherapy. Therefore, ZA enhanced the inhibitory effects of gefitinib on STAT3 and/or p-STAT3 protein expression in the HCC827, HCC827 GR and H1975 cells.

ZA enhances the antitumor effect of gefitinib treatment in NSCLC cells with TKI resistance in vivo. We confirmed that ZA increased the antitumor effects of gefitinib treatment in NSCLC with EGFR mutations in vitro and revealed the mechanisms. We further aimed to ascertain the effects of ZA and gefitinib in vivo.

Fig. 8 shows the effects of ZA and/or gefitinib on HCC827 GR cell-derived tumors in nude mice. We found that ZA or gefitinib slightly suppressed the growth of tumors, but they had no statistical difference compared with the control group $(\mathrm{P}>0.05)$. The combined treatment significantly reduced tumor volume compared with the other tumor groups $(\mathrm{P}<0.05)$ (Fig. 8A). The tumor weight of the combined group was also lower than that in the other groups $(\mathrm{P}<0.05)$ (Fig. 8B). Fig. 8C directly shows that the tumor size of the combined group was smaller than that of the other groups. The drug had no adverse effect on mouse organs and body weight (Fig. 8D and E). The result of IHC showed that ZA and the combined treatment inhibited STAT3 protein phosphorylation in the cytoplasm and nuclei of the tumor cells, and the effect was more obvious in the combined treatment group (Fig. 8F-H).

The results of gefitinib and ZA on H1975 cell-derived tumors were similar to those derived from the HCC827 GR cells (Fig. 9). One difference was that ZA and the combined treatment inhibited STAT3 protein expression in the cytoplasm 

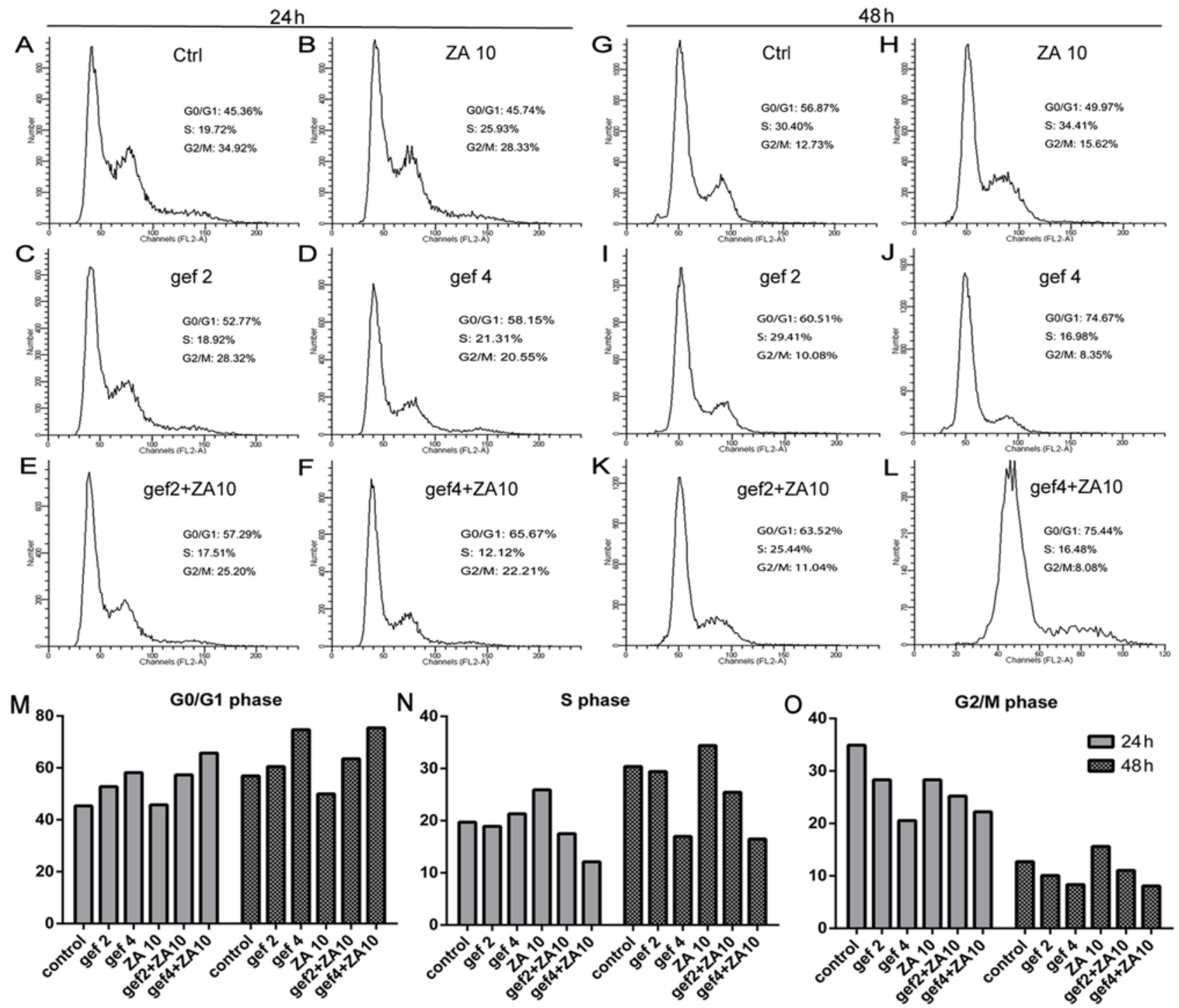

Figure 6. Effect of zoledronic acid (ZA) and gefitinib on the cell cycle of $\mathrm{H} 1975$ cells. H1975 was divided into six groups: control, 2 and $4 \mu \mathrm{M}$ gefitinib, $10 \mu \mathrm{M}$ ZA, 2 and $4 \mu \mathrm{M}$ gefitinib (gef) combined with $10 \mu \mathrm{M}$ ZA. Cells were treated with the indicated agents for $24 \mathrm{~h}$ (A-F) or $48 \mathrm{~h}(\mathrm{G}-\mathrm{L}$ ), and then tumor cells were collected and flow cytometry was used to determine the cell cycle. (M-O) Histograms of tumor cells in the G0/G1, S and G2/M phase after drug treatment for 24 and $48 \mathrm{~h}$, respectively.

and inhibited STAT3 protein phosphorylation in the cytoplasm and nuclei of the tumor cells.

\section{Discussion}

Our study investigated whether ZA could enhance the antitumor effects of gefitinib treatment in NSCLC cells with EGFR mutations and the mechanisms of action. We demonstrated that ZA enhanced the antitumor effects of gefitinib treatment in NSCLC cells with EGFR activating mutation and TKI resistance by regulating the cell cycle, inducing caspase-3 protein expression and inhibiting STAT3 protein expression.

Previous studies found that ZA has antitumor effects on many tumors and the effects are in a dose- and time-dependent manner $(12,19)$. Meanwhile, ZA was also found to have antitumor effects on lung cancer cells $(11,20)$. In contrast, Li et al found that ZA could not induce tumor cell apoptosis in line-1 lung cancer cells even though it could inhibit tumor cell proliferation (21). We considered that the reason was associated with the different lung cancer cell lines used in the different studies. In our study, we found that even a low dose of ZA inhibited tumor cell proliferation and induced apoptosis in NSCLC cells with EGFR activating mutation and TKI resistance and the effects were in a dose-dependent manner.

Studies also suggest that ZA can increase the antitumor effects of targeted therapy. Zhang et al found that ZA combined with sorafenib treatment of primary liver cancer inhibited the growth of tumors and lung metastasis compared with sorafenib (22). Tivantinib (a c-met tyrosine kinase inhibitor) combined with ZA prolonged the time of breast cancer metastasis to bone and improved the survival of breast cancer patients with bone metastasis in vivo (23). Chang et al found that ZA enhanced the antitumor effect of gefitinib treatment in HCC827 cells with EGFR mutations in vitro and in vivo (16). Our study also found that ZA increased the antitumor effect 
A

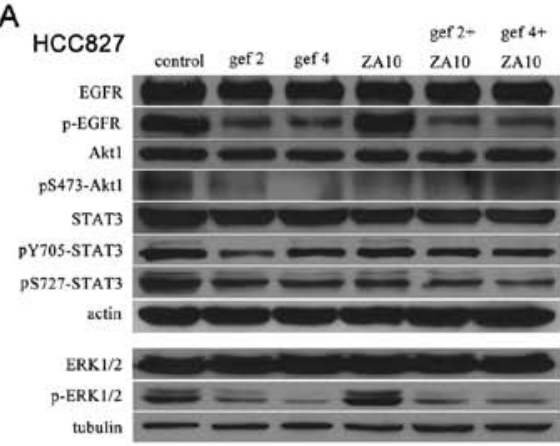

B

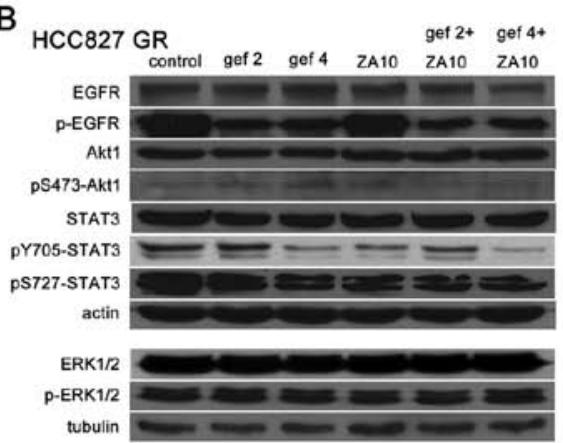

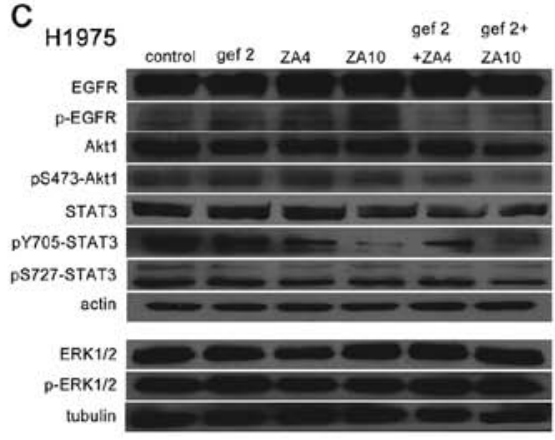

Figure 7. The effect of gefitinib and zoledronic acid (ZA) on EGFR and downstream signaling molecules protein expression of NSCLC. (A) HCC827, (B) HCC827 GR and (C) H1975 cells were divided into six groups and received gefitinib and/or ZA treatment. Collected tumor cells proteins and western blot detected EGFR and downstream signaling molecules protein expression. Gefitinib was 2 and $4 \mathrm{nM}$ in HCC827, 2 and $4 \mu \mathrm{M}$ in $\mathrm{HCC} 827 \mathrm{GR}$ and $2 \mu \mathrm{M}$ in $\mathrm{H} 1975$. ZA was $10 \mu \mathrm{M}$ in HCC827 and HCC827 GR, 4 and $10 \mu \mathrm{M}$ in H1975. HCC827 and HCC827 GR were treated for $24 \mathrm{~h}$ and H1975 for $4 \mathrm{~h}$.
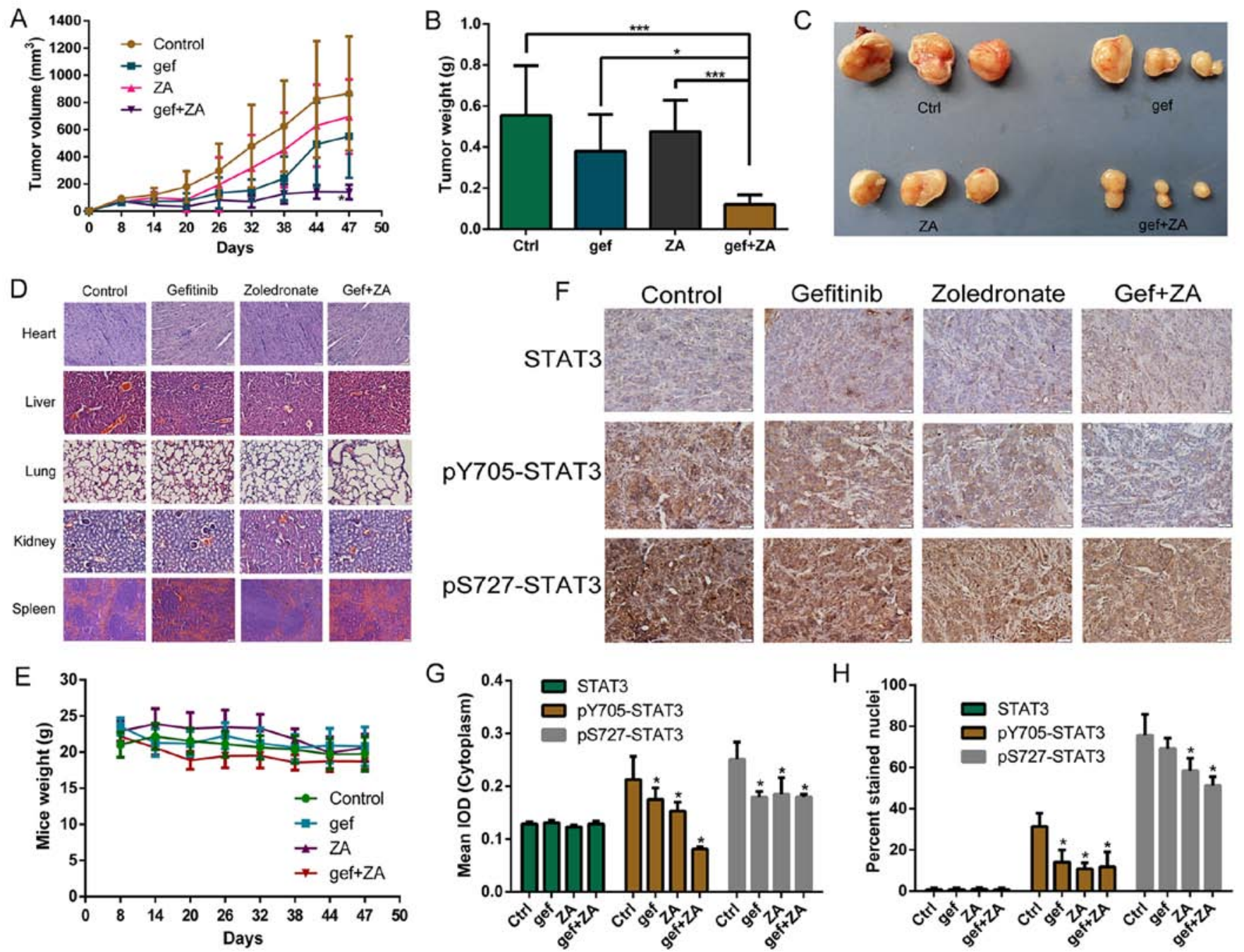

Figure 8. Effects of gefitinib and zoledronic acid (ZA) on HCC827 GR xenograft nude mice. A total of 7x106 HCC 827 GR tumor cells were subcutaneous injected in nude mice (BALB/c, nu/nu). When the tumor volume reached $50 \mathrm{~mm}^{3}$, the mice were divided into four groups administered: vehicle (PEG 400) $0.2 \mathrm{ml} / \mathrm{time} /$ day; gefitinib $50 \mathrm{mg} / \mathrm{kg} /$ day, continuous lavage treatment every day; ZA $80 \mu \mathrm{g} / \mathrm{kg} / \mathrm{day}$, biweekly intraperitoneal injection; or gefitinib combined with ZA treatment at the same time, respectively. (A) Changes in tumor volume during the treatment period. (B) Tumor weight of each group. (C) Representative tumor size in each group. (D) H\&E staining to detect the effects of the agents on mouse organs. (E) Changes in mouse body weight during the treatment period. (F) IHC was used to detect STAT3 protein expression in the tumor tissues. (G and H) Statistical histograms of STAT3 protein expression in the cytoplasm and nuclei, respectively. D and F: magnification x200. ${ }^{*} \mathrm{P}<0.05,{ }^{* * *} \mathrm{P}<0.01$.

of gefitinib treatment in HCC827 cells with EGFR activating mutations in vitro, and we further confirmed that ZA increased the antitumor effect of gefitinib treatment in TKI-resistant NSCLC cells (HCC827 GR and H1975) in vitro and in vivo. 

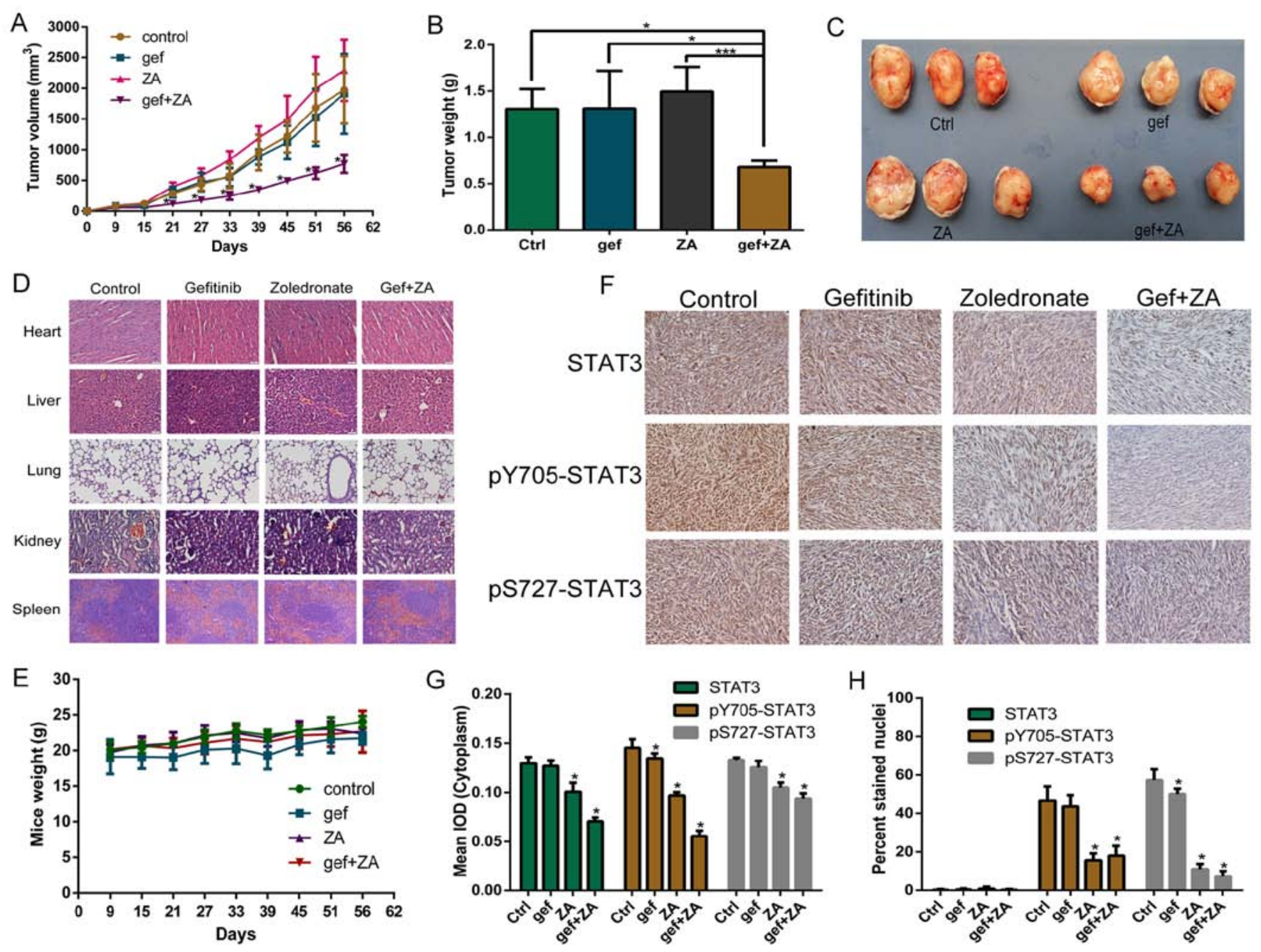

Figure 9. The effect of gefitinib and zoledronic acid (ZA) on H1975 xenograft nude mice. A total of $7 \times 10^{6} \mathrm{H} 1975$ tumor cells were subcutaneous injected in nude mice $(\mathrm{BALB} / \mathrm{c}, \mathrm{nu} / \mathrm{nu})$. When the tumor volume reached $50 \mathrm{~mm}^{3}$, the mice were divided into four groups administered: vehicle (PEG 400$) 0.2 \mathrm{ml} / \mathrm{time} /$ day; gefitinib $50 \mathrm{mg} / \mathrm{kg} / \mathrm{day}$, continuous lavage treatment every day; ZA $80 \mu \mathrm{g} / \mathrm{kg} /$ day, biweekly intraperitoneal injection; or gefitinib combined with ZA treatment at the same time, respectively. (A) Changes in tumor volume during the treatment period. (B) Tumor weight of each group. (C) Representative tumor size in each group. (D) H\&E staining to detect the effects of the agents on mouse organs. (E) Changes in mouse body weight during the treatment period. (F) IHC was used to detect STAT3 protein expression in the tumor tissues. ( $\mathrm{G}$ and $\mathrm{H}$ ) Statistical histograms of STAT3 protein expression in the cytoplasm and nuclei, respectively. D and F: magnification $\mathrm{x} 200 .{ }^{*} \mathrm{P}<0.05,{ }^{* * *} \mathrm{P}<0.01$.

Clinical studies also found that BPs can enhance the antitumor effects combined with targeted therapy. One retrospective clinical study conducted by us assessed the efficacy of BPs combined with EGFR-TKI first-line treatment of advanced NSCLC harboring EGFR mutations. Among 114 patients, 62 with bone metastases (19 patients treated with TKI alone and 43 patients treated with TKI plus BPs) were studied. The combined group had significantly improved mPFS and mOS compared with the TKI group (mPFS: 15 vs. 7 months, $\mathrm{P}=0.001$; mOS: 25 vs. 10 months, $\mathrm{P}=0.001)$. In addition, in 52 patients without bone metastases treated with a TKI alone, and 43 patients with bone metastases treated with TKI + BPs, the mPFS was 15 vs. 12 months $(\mathrm{P}=0.02)$ and the mOS was 25 vs. 21 months $(\mathrm{P}=0.119)$ in the combined group and TKI group, respectively (15). Another two retrospective clinical studies also found that BPs combined with sorafenib/sunitinib treatment in patients with bone metastases from renal cell carcinoma improved the clinical response rate and significantly prolong PFS and OS $(\mathrm{P}<0.05)(24,25)$.
Our findings found that ZA combined with gefitinib induced caspase-3 protein expression and induced apoptosis of NSCLC with EGFR mutations. A previous study demonstrated that erlotinib induced the apoptosis of H3255 cells (L858R mutation) by the mitochondrial-mediated apoptosis pathway, by activating Bax and Bak which are dependent on mitochondrial oxidative phosphorylation (26). In addition, EGFR-TKIs also inhibited PI3K/AKT/survivin and MEK/ERK, and eventually induced BIM expression (27,28). ZA also induced tumor cell apoptosis by inhibiting $\mathrm{Bcl}-2$, inducing BAX and activating caspase-3, caspase-9, and PARP protein expression $(29,30)$. Therefore, gefitinib and ZA may act through different mechanisms of apoptosis, resulting in activated caspase-3, the critical protein of the apoptosis signaling pathway thus inducing tumor cell apoptosis.

EGFR-TKI and ZA affect the tumor cell cycle. EGFR-TKI arrests TKI-sensitive and -resistance lung cancer cells in the G0/G1 phase (31-33). ZA can induce NSCLC cancer cell $S$ phase accumulation $(16,34)$. We also found that gefitinib 
arrested the HCC827, HCC827 GR and H1975 cells in the G0/G1 phase and ZA blocked the three tumor cell lines in the $S$ phase, while the effect of the combined therapy on the cell cycle in the three cell lines was neutralization. Therefore, gefitinib and ZA had different effects on the cell cycle of the three NSCLC cell lines resulting in inhibition of tumor cell proliferation.

EGFR is overexpressed in $60 \%$ of NSCLC tumor tissues. Activation of EGFR causes activation of downstream signaling of PI3K/AKT, MAPK/ERK and JAK/STAT3, promoting tumor proliferation, survival and inhibition of apoptosis $(35,36)$. STAT3 protein is activated at 705 location of tyrosine phosphorylation and induces dimerization, translocation to the cell nucleus and binding of specific DNA elements. The 727 location of serine phosphorylation activation is associated with transcriptional activity (37). EGFR-TKIs inhibit phosphorylation of EGFR tyrosine kinase region, thus inhibiting downstream signaling pathways. Studies have found that the antitumor effect of ZA is associated with inhibition of the activation of Akt and STAT3 (38-40). Our study found that ZA can inhibit Akt and STAT3 protein phosphorylation and STAT3 protein expression in HCC827 cells, and the combined treatment obviously inhibited EGFR and downstream signaling of Akt, ERK1/2 and STAT3 protein phosphorylation and slightly inhibited STAT3 protein expression.

Although NSCLC with EGFR mutations is sensitive to EGFR-TKIs, the majority of patients develop drug resistance. The most common mechanism is the T790M mutation, which accounts for $\sim 50 \%$ of acquired resistance (7). The T790M mutation blocks the combining of TKI to the EGFR tyrosine kinase region and continuously activates downstream signaling pathways (41). We found that ZA inhibits STAT3 protein expression and phosphorylation in H1975 cells, and the combined treatment inhibited EGFR and downstream molecules Akt and STAT3 protein phosphorylation and STAT3 protein expression in vitro. We also confirmed that the combined treatment inhibited STAT3 protein expression and phosphorylation in vivo. Therefore, ZA enhanced the antitumor effect of gefitinib treatment in NSCLC cells with T790M mutations by inhibiting STAT3 and p-STAT3 protein expression.

Another important mechanism of TKI resistance in NSCLC is c-met amplification, accounting for $22 \%$ of the acquired resistance (8). The combining of c-met and the ligand of HGF can activate downstream signaling pathways PI3K/Akt, MAPK/ERK and STAT3 (42). The HCC827 GR cell line is a gefitinib-acquired resistant cell line with c-met amplification (8). Our study found that ZA inhibited STAT3 protein phosphorylation in the HCC 827 GR cells, and the combined treatment inhibited EGFR and downstream molecules Akt and STAT3 protein phosphorylation in vitro. We also confirmed that combined treatment inhibited STAT3 protein phosphorylation in vivo. Therefore, ZA enhanced the antitumor effects of gefitinib treatment in NSCLC cells with c-met amplification by inhibiting STAT3 protein phosphorylation.

As known, ZA induces osteoclast apoptosis by inhibiting the mevalonate pathway. The mevalonate pathway plays an important role in the activation of EGFR and downstream signaling molecules. Drug targeting of the mevalonate pathway can increase the antitumor effect of EGFR-TKI treat- ment in NSCLC with EGFR mutations $(43,44)$. Therefore, ZA enhanced the antitumor effect of gefitinib treatment in NSCLC with EGFR mutations through inhibition of the mevalonate pathway.

Our study has some limitations. i) We detected the effects of ZA and gefitinib on the protein expression of EGFR and downstream signaling molecules (ERK, STAT3 and Akt), but we did not detect the expression of other upstream and downstream proteins. Thus, we did not confirm whether the drug could affect expression of other proteins. ii) A previous study confirmed that ZA can enhance the antitumor effect of gefitinib treatment in HCC827 cells in vivo (16). Therefore, our study did not detect the antitumor effect of both drugs in HCC 827 nude mice and iii) we detected only the expression of STAT3 protein in tumor tissues, therefore expression of other proteins in the tumor tissues were not determined.

In summary, we demonstrated that ZA enhanced the antitumor effects of gefitinib in NSCLC with EGFR activating mutation and TKI resistance by regulation of the tumor cell cycle, induction of caspase-3 protein expression and inhibition of STAT3 protein expression. Our study provides a new treatment strategy for NSCLC patients with EGFR mutations, particularly for TKI-resistant NSCLC.

\section{Acknowledgements}

We thank Novartis Pharma Stein AG who kindly provided the zoledronic acid for this research. The present study was supported by the National Natural Science Foundation of China (no. 81472197).

\section{References}

1. Torre LA, Bray F, Siegel RL, Ferlay J, Lortet-Tieulent J and Jemal A: Global cancer statistics, 2012. CA Cancer J Clin 65: 87-108, 2015.

2. Rosell R, Moran T, Queralt C, Porta R, Cardenal F, Camps C, Majem M, Lopez-Vivanco G, Isla D, Provencio M, et al; Spanish Lung Cancer Group: Screening for epidermal growth factor receptor mutations in lung cancer. N Engl J Med 361: 958-967, 2009.

3. Wu YL, Zhong WZ, Li LY, Zhang XT, Zhang L, Zhou CC, Liu W, Jiang B, Mu XL, Lin JY, et al: Epidermal growth factor receptor mutations and their correlation with gefitinib therapy in patients with non-small cell lung cancer: A meta-analysis based on updated individual patient data from six medical centers in mainland China. J Thorac Oncol 2: 430-439, 2007.

4. Gazdar AF: Activating and resistance mutations of EGFR in non-small cell lung cancer: Role in clinical response to EGFR tyrosine kinase inhibitors. Oncogene 28 (Suppl 1): S24-S31, 2009.

5. Maemondo M, Inoue A, Kobayashi K, Sugawara S, Oizumi S, Isobe $\mathrm{H}$, Gemma A, Harada M, Yoshizawa H, Kinoshita I, et al; North-East Japan Study Group: Gefitinib or chemotherapy for non-small cell lung cancer with mutated EGFR. N Engl J Med 362: 2380-2388, 2010.

6. Lin Y, Wang $\mathrm{X}$ and Jin H: EGFR-TKI resistance in NSCLC patients: Mechanisms and strategies. Am J Cancer Res 4: 411-435, 2014.

7. Kosaka T, Yatabe Y, Endoh H, Yoshida K, Hida T, Tsuboi M, Tada H, Kuwano H and Mitsudomi T: Analysis of epidermal growth factor receptor gene mutation in patients with non-small cell lung cancer and acquired resistance to gefitinib. Clin Cancer Res 12: 5764-5769, 2006.

8. Engelman JA, Zejnullahu K, Mitsudomi T, Song Y, Hyland C, Park JO, Lindeman N, Gale CM, Zhao X, Christensen J, et al: MET amplification leads to gefitinib resistance in lung cancer by activating ERBB3 signaling. Science 316: 1039-1043, 2007. 
9. Luckman SP, Coxon FP, Ebetino FH, Russell RGG and Rogers MJ: Heterocycle-containing bisphosphonates cause apoptosis and inhibit bone resorption by preventing protein prenylation: Evidence from structure-activity relationships in J774 macrophages. J Bone Miner Res 13: 1668-1678, 1998.

10. Dunford JE, Thompson K, Coxon FP, Luckman SP, Hahn FM, Poulter CD, Ebetino FH and Rogers MJ: Structure-activity relationships for inhibition of farnesyl diphosphate synthase in vitro and inhibition of bone resorption in vivo by nitrogen-containing bisphosphonates. J Pharmacol Exp Ther 296: 235-242, 2001.

11. Di Salvatore M, Orlandi A, Bagalà C, Quirino M, Cassano A, Astone A and Barone C: Anti-tumour and anti-angiogenetic effects of zoledronic acid on human non-small cell lung cancer cell line. Cell Prolif 44: 139-146, 2011.

12. Morgan $\mathrm{G}$ and Lipton A: Antitumor effects and anticancer applications of bisphosphonates. Semin Oncol 37 (Suppl 2): S30-S40, 2010.

13. Kijima T, Koga F, Fujii Y, Yoshida S, Tatokoro M and Kihara K: Zoledronic acid sensitizes renal cell carcinoma cells to radiation by downregulating STAT1. PLoS One 8: e64615, 2013.

14. Fukai J, Koizumi $F$ and Nakao N: Enhanced anti-tumor effect of zoledronic acid combined with temozolomide against human malignant glioma cell expressing $\mathrm{O}^{6}$-methylguanine DNA methyltransferase. PLoS One 9: e104538, 2014.

15. Huang CY, Wang L, Feng CJ, Yu P and Wang YS: Cooperation of bisphosphonates with tyrosine kinase inhibitors in advanced non-small cell lung cancer with EGFR activation mutation: A retrospective study. J Clin Oncol 32: e19073, 2014.

16. Chang JW, Hsieh JJ, Shen YC, Yeh KY, Wang CH, Li YY and Hsu T: Bisphosphonate zoledronic acid enhances the inhibitory effects of gefitinib on EGFR-mutated non-small cell lung carcinoma cells. Cancer Lett 278: 17-26, 2009.

17. Chen W, Shen X, Xia X, Xu G, Ma T, Bai X and Liang T: NSC 74859-mediated inhibition of STAT3 enhances the anti-proliferative activity of cetuximab in hepatocellular carcinoma. Liver Int 32: 70-77, 2012.

18. Wang M, Chen GY, Song HT, Hong X, Yang ZY and Sui GJ: Significance of CXCR4, phosphorylated STAT3 and VEGF-A expression in resected non-small cell lung cancer. Exp Ther Med 2: 517-522, 2011

19. Fromigue O, Lagneaux L and Body J-J: Bisphosphonates induce breast cancer cell death in vitro. J Bone Miner Res 15: 2211-2221, 2000.

20. Matsumoto S, Kimura S, Segawa H, Kuroda J, Yuasa T, Sato K, Nogawa M, Tanaka F, Maekawa T and Wada H: Efficacy of the third-generation bisphosphonate, zoledronic acid alone and combined with anti-cancer agents against small cell lung cancer cell lines. Lung Cancer 47: 31-39, 2005.

21. Li YY, Chang JW, Chou WC, Liaw CC, Wang HM, Huang JS, Wang $\mathrm{CH}$ and Yeh KY: Zoledronic acid is unable to induce apoptosis, but slows tumor growth and prolongs survival for non-small-cell lung cancers. Lung Cancer 59: 180-191, 2008.

22. Zhang W, Zhu XD, Sun HC, Xiong YQ, Zhuang PY, Xu HX, Kong LQ, Wang L, Wu WZ and Tang ZY: Depletion of tumor-associated macrophages enhances the effect of sorafenib in metastatic liver cancer models by antimetastatic and antiangiogenic effects. Clin Cancer Res 16: 3420-3430, 2010.

23. Previdi S, Scolari F, Chilà R, Ricci F, Abbadessa G and Broggini M: Combination of the c-Met inhibitor tivantinib and zoledronic acid prevents tumor bone engraftment and inhibits progression of established bone metastases in a breast xenograft model. PLoS One 8: e79101, 2013.

24. Beuselinck B, Wolter P, Karadimou A, Elaidi R, Dumez H, Rogiers A, Van Cann T, Willems L, Body JJ, Berkers J, et al: Concomitant oral tyrosine kinase inhibitors and bisphosphonates in advanced renal cell carcinoma with bone metastases. Br J Cancer 107: 1665-1671, 2012

25. Keizman D, Ish-Shalom M, Pili R, Hammers H, Eisenberger MA, Sinibaldi V, Boursi B, Maimon N, Gottfried M, Hayat H, et al: Bisphosphonates combined with sunitinib may improve the response rate, progression free survival and overall survival of patients with bone metastases from renal cell carcinoma. Eur J Cancer 48: 1031-1037, 2012.

26. Ling $\mathrm{YH}$, Lin $\mathrm{R}$ and Perez-Soler R: Erlotinib induces mitochondrial-mediated apoptosis in human H3255 non-small-cell lung cancer cells with epidermal growth factor receptorL858R mutation through mitochondrial oxidative phosphorylation-dependent activation of BAX and BAK. Mol Pharmacol 74: 793-806, 2008.
27. Okamoto K, Okamoto I, Okamoto W, Tanaka K, Takezawa K, Kuwata K, Yamaguchi H, Nishio K and Nakagawa K: Role of survivin in EGFR inhibitor-induced apoptosis in non-small cell lung cancers positive for EGFR mutations. Cancer Res 70: 10402-10410, 2010.

28. Gong YX, Somwar R, Politi K, Balak M, Chmielecki J, Jiang X and Pao W: Induction of BIM is essential for apoptosis triggered by EGFR kinase inhibitors in mutant EGFR-dependent lung adenocarcinomas. PLoS Med 4: e294, 2007.

29. Senaratne SG, Pirianov G, Mansi JL, Arnett TR and Colston KW: Bisphosphonates induce apoptosis in human breast cancer cell lines. Br J Cancer 82: 1459-1468, 2000.

30. Tassone P, Tagliaferri P, Viscomi C, Palmieri C, Caraglia M, D'Alessandro A, Galea E, Goel A, Abbruzzese A, Boland CR, et al: Zoledronic acid induces antiproliferative and apoptotic effects in human pancreatic cancer cells in vitro. $\mathrm{Br} \mathrm{J}$ Cancer 88: 1971-1978, 2003

31. Wu M, Yuan Y, Pan YY and Zhang Y: Antitumor activity of combination treatment with gefitinib and docetaxel in EGFR-TKI-sensitive, primary resistant and acquired resistant human non-small cell lung cancer cells. Mol Med Rep 9: 2417-2422, 2014.

32. Mu X, Zhang Y, Qu X, Hou K, Kang J, Hu X and Liu Y: Ubiquitin ligase Cbl-b is involved in icotinib (BPI-2009H)-induced apoptosis and G1 phase arrest of EGFR mutation-positive non-small cell lung cancer. BioMed Res Int 2013: 726375, 2013.

33. Li T, Ling YH, Goldman ID and Perez-Soler R: Scheduledependent cytotoxic synergism of pemetrexed and erlotinib in human non-small cell lung cancer cells. Clin Cancer Res 13: 3413-3422, 2007

34. Li YY, Chang JW, Liu YC, Wang CH, Chang HJ, Tsai MC, Su SP and Yeh KY: Zoledronic acid induces cell-cycle prolongation in murine lung cancer cells by perturbing cyclin and Ras expression. Anticancer Drugs 22: 89-98, 2011.

35. Lemmon MA and Schlessinger J: Cell signaling by receptor tyrosine kinases. Cell 141: 1117-1134, 2010.

36. Sordella R, Bell DW, Haber DA and Settleman J: Gefitinibsensitizing EGFR mutations in lung cancer activate anti-apoptotic pathways. Science 305: 1163-1167, 2004.

37. Wen Z, Zhong Z and Darnell JE Jr: Maximal activation of transcription by Stat 1 and Stat 3 requires both tyrosine and serine phosphorylation. Cell 82: 241-250, 1995.

38. Kiper HD, Tezcanli Kaymaz B, Gokbulut AA, Selvi N, Avci CB, Kosova B, Iskender G, Yandim MK, Gunduz C, Sahin F, et al: STAT pathway in the regulation of zoledronic acid-induced apoptosis in chronic myeloid leukemia cells. Biomed Pharmacother 67: 527-532, 2013.

39. Reuben JS, Dinh L, Lee J, Stateson J, Kamara H, Xiang L and Opperman LA: Bisphosphonates inhibit phosphorylation of signal transducer and activator of transcription 3 and expression of suppressor of cytokine signaling 3: Implications for their effects on innate immune function and osteoclastogenesis. Oral Surg Oral Med Oral Pathol Oral Radiol Endod 111: 196-204, 2011.

40. Koto K, Murata H, Kimura S, Sawai Y, Horie N, Matsui T, Ryu K, Ashihara E, Maekawa T, Kubo T, et al: Zoledronic acid significantly enhances radiation induced apoptosis against human fibrosarcoma cells by inhibiting radioadaptive signaling. Int J Oncol 42: 525-534, 2013.

41. Yun CH, Mengwasser KE, Toms AV, Woo MS, Greulich H, Wong KK, Meyerson M and Eck MJ: The T790M mutation in EGFR kinase causes drug resistance by increasing the affinity for ATP. Proc Natl Acad Sci USA 105: 2070-2075, 2008.

42. Robinson KW and Sandler AB: The role of MET receptor tyrosine kinase in non-small cell lung cancer and clinical development of targeted anti-MET agents. Oncologist 18: 115-122, 2013.

43. Ringerike T, Blystad FD, Levy FO, Madshus IH and Stang E: Cholesterol is important in control of EGF receptor kinase activity but EGF receptors are not concentrated in caveolae. J Cell Sci 115: 1331-1340, 2002.

44. Mantha AJ, Hanson JEL, Goss G, Lagarde AE, Lorimer IA and Dimitroulakos J: Targeting the mevalonate pathway inhibits the function of the epidermal growth factor receptor. Clin Cancer Res 11: 2398-2407, 2005. 